\title{
Template-free synthesis of mesoporous phenylsulfonic acid functionalized silica
}

\author{
Xueguang Wang ${ }^{a, b}$, Soofin Cheng ${ }^{a, *}$, Jerry C.C. Chan ${ }^{\text {a }}$, John C.H. Chao ${ }^{\text {a }}$ \\ ${ }^{a}$ Department of Chemistry, National Taiwan University, No. 1, Roosevelt Road, Sec. 4, Taipei 106, Taiwan \\ ${ }^{\mathrm{b}}$ Supercritical Fluid Research Center, National Institute for Advanced Industrial Science and Technology, 4-2-1, Nigatake, Miyagino-ku, \\ Sendai 983-8551, Japan
}

Received 12 June 2006; received in revised form 20 July 2006; accepted 21 July 2006

Available online 1 September 2006

\begin{abstract}
Mesoporous silica functionalized with phenylsulfonic acid was prepared by a simple template-free co-condensation of tetraethyl orthosilicate (TEOS) and 2-(4-chlorosulfonylphenyl)ethyltrimethoxysilane (CETS) under strong acidic condition. The obtained materials with 3-15 mol\% loadings of phenylsulfonic acid were X-ray amorphous, but had large surface areas $\left(420-620 \mathrm{~m}^{2} / \mathrm{g}\right)$ and narrow pore-size distributions (0.3-1.0 nm PSD, estimated from the peak width at half maximum height) with pore diameters in the range of 3.5-5.0 nm. TEOS hydrolysis prior to the addition of CETS was found to be important in order to obtain functionalized silica materials of large mesopores and pore volumes. IR, TG and solid state NMR studies showed that most of the phenylsulfonic acid groups were incorporated into the silica materials without decomposition during the synthesis procedure. Moreover, most of the sulfonic acid sites are accessible by large cations such as tetramethylammonium $\left(\mathrm{TMA}^{+}\right)$and tetrabutylammonium $\left(\mathrm{TBA}^{+}\right)$ions. The materials were examined as acid catalysts in esterification of acetic acid with methanol and acetalization of chlorobenzaldehyde with methanol. The results showed that the functionalized amorphous silica materials synthesized with TEOS pre-hydrolysis had similar catalytic activities as that of phenylsulfonic acid-functionalized SBA-15, but higher activities than those of the counterparts synthesized without TEOS pre-hydrolysis or the propylsulfonic acid functionalized SBA-15.
\end{abstract}

(C) 2006 Elsevier Inc. All rights reserved.

Keywords: Phenylsulfonic; Silica; Mesoporous; Template-free; Pre-hydrolysis; Acid catalyst

\section{Introduction}

The hybrid organic-inorganic materials with organic functional groups have attracted much attention owing to their potential applications in separation technology [1,2], catalysis [3-5], nanoelectronics and sensors [6,7], and as intermediates for further modification of pore structures $[8,9]$. In recent years, many researches have focused on ordered organic group functionalized silica-based mesoporous materials with relatively uniform pore sizes and high surface areas. They were generally prepared either

\footnotetext{
${ }^{*}$ Corresponding author. Tel.: +886223638017; fax: +886223636359.

E-mail addresses: Wang-XG@aist.go.jp (X. Wang), chem1031@ntu. edu.tw (S. Cheng).
}

via post-synthetic grafting with organosilane [10-12] or via co-condensation of a tetraalkoxysilane and organosilane [13-15]. The co-condensation method has advantages over the post-synthesis pathway because it minimizes processing steps, provides a more uniform distribution of the organic functionalities [16], and achieves a relatively high loading of organic groups without closing the framework mesopores $[15,17]$. However, the direct synthesis of ordered mesoporous silica materials with organic functional groups require the use of large amount of organic solvents such as ethanol or acetone to remove the pore-directing templates. Besides, the mechanical strength of the resultant ordered mesoporous organo-functionalized materials is often concerned. After chemical reactions, the ordering of the mesopores often decreases or completely collapses. The 
mechanical strength was believed to improve with rigid cross-linking skeletons by preparing the organic functionalized silica through direct hydrolysis of the precursors without using the template agents [18-22]. However, amorphous materials are usually obtained and the accessibility of the functional groups becomes the main concern.

Strong solid acids are considered an environmentally friendly alternative for the hazardous and corrosive mineral acid catalysts such as $\mathrm{H}_{2} \mathrm{SO}_{4}, \mathrm{HF}$ and $\mathrm{ClSO}_{3} \mathrm{H}$ [23-26] commonly used in many industrial processes. Acidic ion-exchange polymer resins such as Nafion resin with a high acid strength have been shown to be an effective catalyst for a wide range of acid-catalyzed reactions [2729]. However, the value of the surface area of the resin is practically negligible $\left(0.02 \mathrm{~m}^{2} \mathrm{~g}^{-1}\right.$ or less $)$ and most of the active sites are buried within the polymer matrix. As a result, the sites are inaccessible or poorly accessible under many reaction conditions and low catalytic activities were observed. As an alternative, the ordered mesoporous silica materials covalent-functionalized with aliphatic or aromatic sulfonic acid groups by post-synthesis or co-condensation have been reported and successfully used in several acid-catalyzed reactions [30-42]. The catalytic activities of solid acid catalysts are also dramatically influenced by the acid strength [40-42]. Compared with aliphatic sulfonic acid groups, aromatic sulfonic acid groups with a phenyl group adhered to the sulfonic group usually show higher acid strength and greater catalytic reactivities in acidcatalyzed reactions, such as in the Fries rearrangement of phenyl acetate and Beckmann rearrangement of cyclohexanone oxime $[40,41]$. Comparatively, only few reports concerning the use of sulfonic acid-functionalized amorphous silica materials as acid catalysts due to the wide distribution in pore diameters and void volumes $[19,21,43-46]$. It is expected that sulfonic acid-functionalized amorphous silica with a narrow pore distribution as well as large surface area will be a promising acid catalyst from the practical viewpoint.

In this paper, we prepared amorphous silica materials with sulfonic acid functional groups through a simple cocondensation of 2-(4-chlorosulfonylphenyl)ethyltrimethoxysilane (CETS) and tetraethoxysilane (TEOS) under strong acid condition without the addition of any structure-directing agents. The chlorosulfonyl groups $\left(-\mathrm{SO}_{2} \mathrm{Cl}\right)$ were in situ hydrolyzed to the corresponding sulfonic acid groups under the co-condensation condition. The narrow pore-size distribution was achieved by pre-hydrolysis of TEOS for proper period of time before the addition of CETS. The obtained materials were characterized by $\mathrm{N}_{2}$ adsorption-desorption measurement, FTIR, TG, solid state NMR, and elemental analysis (EA). The accessibility of sulfonic acids in the materials was determined by ion-exchange capacities of cations of various sizes including sodium, tetramethylammonium (TMA) and tetrabutylammonium (TBA) ions. Esterification of acetic acid with methanol and acetalization of chlorobenzaldehyde with methanol were used to test the catalytic reactivity of the materials. The obtained materials were compared with propyl- and phenyl-sulfonic acid functionalized SBA-15 materials in terms of the accessibility of sulfonic acids and the catalytic activities.

\section{Experimental section}

\subsection{Chemicals and synthesis}

3-Mercaptopropyltrimethoxysilane (MPTS) and Surfactant P123 $\left(\mathrm{EO}_{20} \mathrm{PO}_{70} \mathrm{EO}_{20}, M_{\mathrm{av}}=5800\right)$ were purchased from Aldrich, and other chemicals of reagent grade were from Acros. All chemicals were used as received.

The phenylsulfonic acid functionalized amorphous silica materials were prepared by co-condensation of TEOS and CETS under strong acidic condition. In the typical procedure, $8 \mathrm{~g}$ of TEOS was first added into an opening beaker with $125 \mathrm{~g}$ of $2.0 \mathrm{M} \mathrm{HCl}$ solution and hydrolyzed at $40{ }^{\circ} \mathrm{C}$ under stirring for $20 \mathrm{~h}$. At this time the solution was found to be viscous. The appropriate amount of CETS (50\% solution in dichloromethane) was slowly added in the solution and the mixture was kept stirring at the same temperature until the water was evaporated out, and finally, the solid was dried overnight at $100{ }^{\circ} \mathrm{C}$ and ground to powder. The CETS/(TEOS + CETS) molar ratio was varied in 0 $15 \%$. The resultant samples are denoted as $\mathrm{SiO}_{2}-\mathrm{phSO}_{3}$ $\mathrm{H}-x-\mathrm{P}$, where $\mathrm{P}$ represents "pre-hydrolysis of TEOS" and $x$ is the molar percentage of CETS/(TEOS + CETS). For example, $\mathrm{SiO}_{2}-\mathrm{phSO}_{3} \mathrm{H}-10-\mathrm{P}$ represents the sample prepared with TEOS pre-hydrolysis and CETS/(TEOS + CETS $)=10 \mathrm{~mol} \%$. On the other hand, the counterpart samples prepared by simultaneous addition of TEOS and CETS, that is without pre-hydrolysis of TEOS, were denoted as $\mathrm{SiO}_{2}-\mathrm{phSO}_{3} \mathrm{H}-x$.

Phenylsulfonic acid-functionalized SBA-15 materials were prepared according to the procedures mentioned in Ref. [15]. The P123 template in the as-made SBA-15 materials was removed by refluxing with ethanol. Finally, the materials were filtered, washed several times with water and ethanol and dried at $50{ }^{\circ} \mathrm{C}$. The samples were denoted as SBA-phSO ${ }_{3} \mathrm{H}-5,10$ and 15 for the materials with CETS/ $($ TEOS + CETS $)=5,10$ and $15 \mathrm{~mol} \%$, respectively. Propylsulfonic-functionalized SBA-15 with $10 \mathrm{~mol} \%$ MPTS (denoted as $\mathrm{SBA}-\mathrm{PrSO}_{3} \mathrm{H}-10$ ) was also prepared according to the literature [30].

\subsection{Sample characterization}

$\mathrm{N}_{2}$ adsorption-desorption isotherms were measured using a Micromeritics Tristar 3000 system at liquid nitrogen temperature. Before the measurements, the samples were degassed at $120^{\circ} \mathrm{C}$ overnight. The specific surface areas were evaluated using Brunauer-Emmett-Teller (BET) method in the $p / p_{0}$ range of $0.05-0.3$. Pore-size distribution curves were calculated using the desorption branch of the isotherms and the Barrett-Joyner-Halenda (BJH) method. The $D_{\mathrm{p}}$ values of pore diameters were obtained from the peak positions of the distribution curves, 
and average pore diameter $\left(D_{\mathrm{a}}\right)$ values were calculated by BJH method. The pore-size distribution (PSD) was determined from the peak width at half maximum height of the BJH peak. The pore volume was taken at the $p / p_{0}$ $=0.990$ point.

X-ray powder diffraction (XRD) patterns were obtained on a PANalytical X'Pert Pro diffractometer using $\mathrm{Cu} \mathrm{K} \alpha$ radiation $(\lambda=1.5418 \AA)$ at $45 \mathrm{kV}$ and $40 \mathrm{~mA}$. Thermogravimetric (TG) analyses were carried out on a Netzsch TG 951 thermogravimetric analyzer with a heating speed of $10{ }^{\circ} \mathrm{C} / \mathrm{min}$ in a $50 \mathrm{ml} / \mathrm{min}$ air flow. Fourier transform infrared (FTIR) spectra were taken on a Nicolet MagnaIR 550 spectrometer with a resolution of $2 \mathrm{~cm}^{-1}$ using the $\mathrm{KBr}$ method. $\mathrm{S}$ elemental analyses (EA) were performed on a Heraeus CHNS elemental analyzer. The ionexchange capacities of the sulfonic mesoporous materials were determined using the solid acid titration technique $[30,40,41]$.

Aqueous solutions of sodium chloride $(\mathrm{NaCl}, 2 \mathrm{M})$, tetramethylammonium chloride (TMAC, $0.05 \mathrm{M}$ ) and tetrabutylammonium chloride (TBAC, $0.05 \mathrm{M}$ ) were used as ion-exchange agents to determine the acid capacities of the materials. In a typical experiment, $0.10 \mathrm{~g}$ of solid treated at $200{ }^{\circ} \mathrm{C}$ for one day was added to $20 \mathrm{ml}$ of aqueous solution containing the corresponding salt. The resultant suspension was equilibrated for $6 \mathrm{~h}$, and then filtered and washed with small amount of water and finally, the filtrate was titrated potentiometrically by aqueous solution of $0.01 \mathrm{M} \mathrm{NaOH}$

The NMR experiments were carried out at ${ }^{29} \mathrm{Si},{ }^{13} \mathrm{C}$ and ${ }^{1} \mathrm{H}$ frequencies of 59.6, 75.5 and $300.1 \mathrm{MHz}$, respectively, on a Bruker DSX300 NMR spectrometer equipped with a commercial $7 \mathrm{~mm}$ MAS-NMR probe. All spectra were measured at room temperature. The magic-angle spinning frequencies were set to $5 \mathrm{kHz}$ for all experiments and the variation was limited to $\pm 3 \mathrm{~Hz}$ using a commercial pneumatic control unit. Chemical shifts were externally referenced to tetramethylsilane for ${ }^{29} \mathrm{Si}$ and ${ }^{13} \mathrm{C}$. For the ${ }^{29} \mathrm{Si}$ Bloch-decay experiment, the recycle delay was set to $60 \mathrm{~s}$. ${ }^{13} \mathrm{C}\left\{{ }^{1} \mathrm{H}\right\}$ cross-polarization spectra were measured with a recycle delay of $4 \mathrm{~s}$ and the contact times were $1.5 \mathrm{~ms}$.

\subsection{Catalytic reactions}

Esterification of carboxylic acids with alcohols and acetalization of carbonyl compounds with methanol are commonly used to test the catalytic acitivities of solid acid catalysts containing sulfonic acid groups $[18,19]$. Before the reaction, all the catalysts were heated at $200^{\circ} \mathrm{C}$ for one day to remove adsorbed water. The esterification of acetic acid with methanol was carried out in a two-neck flask of $50 \mathrm{ml}$, which was placed in a thermostatic bath, with a magnetic stirrer and a reflux condenser. In a typical experiment, $0.15 \mathrm{~mol}(9.08 \mathrm{~g})$ of acetic acid and $0.15 \mathrm{~mol}$ $(4.81 \mathrm{~g})$ of methanol was mixed under vigorous stirring while heating to $50^{\circ} \mathrm{C}$ of the reaction temperature and then $0.15 \mathrm{~g}$ of the dried catalyst was added into the reaction mix- ture. The initial reaction rates were determined during the first $10 \mathrm{~min}$ of the reaction. The conversions of the reaction during this period were less than $13 \mathrm{~mol} \%$. Because esterification could proceed in the absence of the solid catalyst, the initial rates for esterification over the catalysts (mol/ $\mathrm{g} \mathrm{s})$ were referred to those subtracted by the initial homogeneous rates during the first $10 \mathrm{~min}$ of the reactions. The liquid products were separated from the reaction mixture at appropriate reaction intervals with a filtering syringe and analyzed using a Chrompak CP 9000 gas chromatograph (GC) equipped with a $30 \mathrm{~m} \times 0.53 \mathrm{~mm}$ RTX-50 capillary column and FID detector, and identified by GC-mass spectrometry (HP5971 mass spectrometer connected with a $30 \times 0.25 \mathrm{~mm}$ RTX-50 capillary column). Quantitative analysis was based on the calculated response factors for the appropriate reactants and corresponding reaction products. The overall mass balance was more than $98 \%$.

Acetalization of chlorobenzaldehyde with methanol was performed in a one-neck flask of $50 \mathrm{ml}$. Ten millimoles $(1.41 \mathrm{~g})$ of chlorobenzaldehyde was dissolved in $25 \mathrm{ml}$ methanol (ca. $0.6 \mathrm{~mol}$ ) under vigorous stirring and the mixture was kept at $30^{\circ} \mathrm{C}$ when $20 \mathrm{mg}$ of the catalyst was added in. $0.4 \mathrm{~g}$ of anisole was used as internal standard. Initial reaction rates were determined during the first $5 \mathrm{~min}$ of the reaction. The conversions of the reaction during this period were less than $25 \mathrm{~mol} \%$. The overall mass balance based on the chlorobenzaldehyde reactant was more than $95 \%$.

\section{Results and discussion}

\subsection{Characterization of sulfonic acid-functionalized amorphous silica}

The small angle X-ray diffraction patterns of as-synthesized materials showed that the samples synthesized without pore-directing agent had no diffraction peaks in the range of $2 \theta<6^{\circ}$, indicating no long-range ordering of the mesopores in these materials. In contrast, the materials prepared by P123-templated method showed one intense peak and two weak peaks, corresponding to $(100),(110)$ and (200) diffractions, respectively, of SBA-15 materials with ordered hexagonal arrays of one-dimensional channel structure [47].

The $\mathrm{N}_{2}$ adsorption-desorption isotherms of the phenylsulfonic acid-functionalized materials synthesized via template-free route are illustrated in Figs. 1A and 2A, for those with and without TEOS pre-hydrolysis, respectively. All the samples exhibit characteristic type IV isotherms with type $\mathrm{H} 2$ hysteresis loops according to the IUPAC classification. The adsorption-desorption hystereses take place in the $p / p_{0}$ range of $0.40-0.55$, demonstrating that the materials contain mesopores with relatively uniform pore size. The materials prepared with TEOS pre-hydrolysis show capillary condensation and evaporation at relatively higher pressures in comparison to those prepared without 

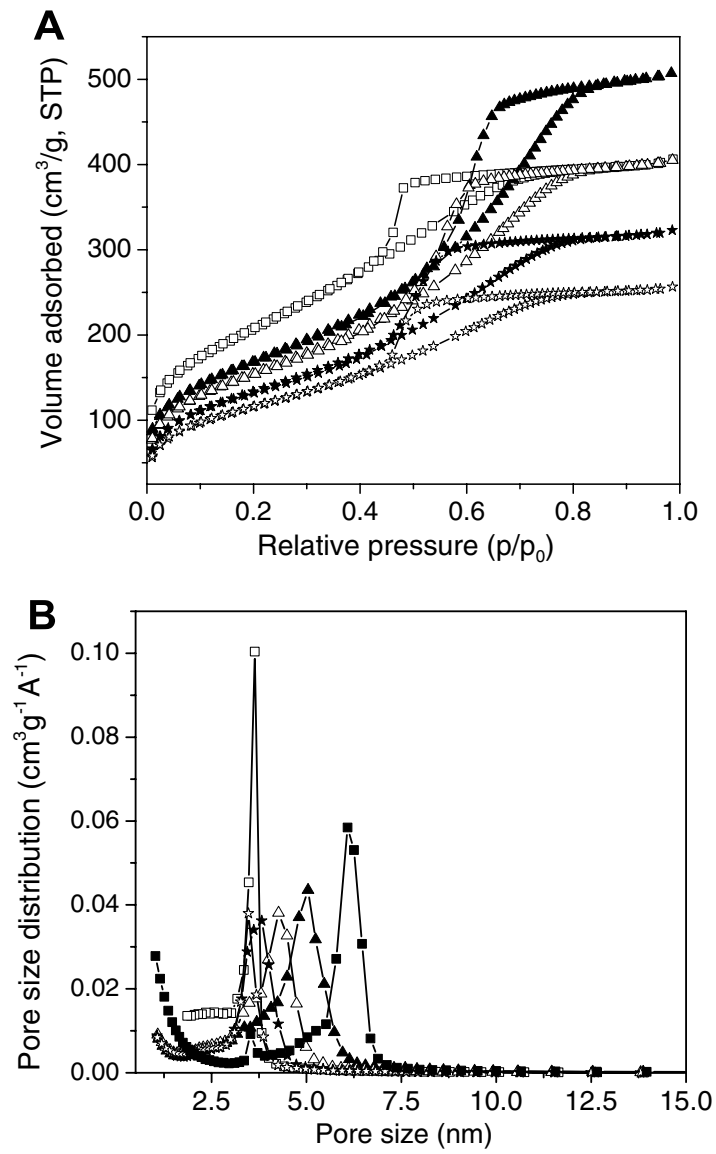

Fig. 1. Nitrogen adsorption-desorption isotherms (A) and BJH pore-size distribution profiles (B) of the phenylsulfonic acid functionalized silica prepared with TEOS pre-hydrolysis containing different CETS contents in the initial mixture, $\mathrm{SiO}_{2}-\mathrm{phSO}_{3} \mathrm{H}-x$-P with $x=0$ (open square), 3 (solid triangle), 7 (open triangle), 10 (solid star), 15 (open star), and in comparison to that of SBA- $\mathrm{PrSO}_{3} \mathrm{H}-10$ (solid square).

TEOS pre-hydrolysis and that of pure silica ( $0 \%$ CETS). It is also noticed that among the functionalized materials with TEOS pre-hydrolysis $\left(\mathrm{SiO}_{2}-\mathrm{phSO}_{3} \mathrm{H}-x\right.$-P series), the capillary condensation shifted toward lower pressures and the amount of adsorbed $\mathrm{N}_{2}$ decreased with the increase in CETS content. These results indicate that the $\mathrm{N}_{2}$ adsorption capacity is strongly influenced by the CETS content and TEOS pre-hydrolysis.

BJH pore size analysis (Figs. 1B and 2B) shows that the functionalized materials prepared with TEOS pre-hydrolysis contain larger mesopores than that of pure silica gel or those synthesized without TEOS pre-hydrolysis. Moreover, the functionalized materials prepared with TEOS prehydrolysis have reasonably narrow pore-size distributions (PSD) in the range of $0.3-1.0 \mathrm{~nm}$ (as shown in Table 1). However, the peak position of the pore size shifts toward lower values and the PSD becomes narrower with the increase of CETS content in the synthesis mixture for the materials prepared with TEOS pre-hydrolysis. That is likely due to the occupation of the pore space by the organic functional groups.
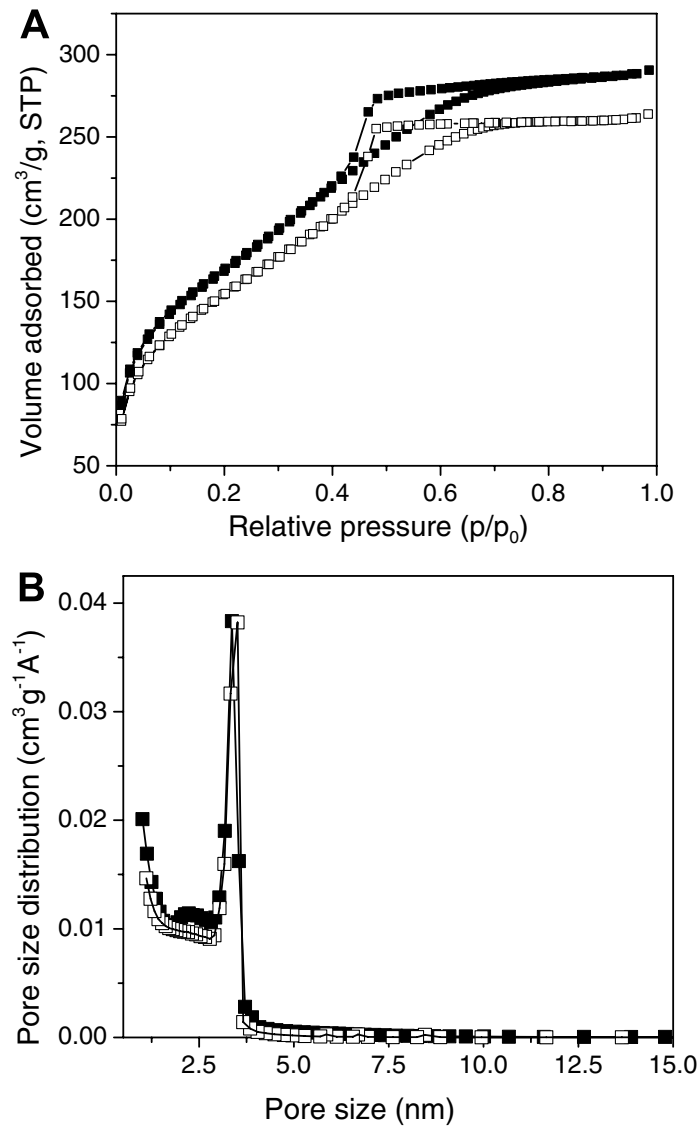

Fig. 2. Nitrogen adsorption-desorption isotherms (A) and BJH pore-size distribution (B) of the phenylsulfonic acid functionalized silica prepared without TEOS pre-hydrolysis. (ם) $\mathrm{SiO}_{2}-$ phSO$_{3} \mathrm{H}-7$ and ( $\square$ ) $\mathrm{SiO}_{2}-$ $\mathrm{phSO}_{3} \mathrm{H}-10$.

The basic physico-chemical and textural properties of the functionalized materials are summarized in Table 1. All the functionalized samples prepared with TEOS prehydrolysis have relatively high surface areas, large BJH pore diameters ( $D_{\mathrm{p}}$ values) and large pore volumes. Moreover, the BJH peak pore diameter $\left(D_{\mathrm{p}}\right)$ and the average pore diameter $\left(D_{\mathrm{a}}\right)$ are similar, implying that these materials contain uniform mesoporous structures, as also shown in the $\mathrm{N}_{2}$ sorption isotherms in Fig. 1A. It is also noticeable that the addition of small amount of organosilane precursor to the synthesis mixture has great influence on the pore sizes and pore volumes of the resultant silica materials. In comparison to those values of pure silica gel, the $\mathrm{BJH}$ pore size increases dramatically from $3.6 \mathrm{~nm}$ to $5.0 \mathrm{~nm}$ when $3 \mathrm{~mol} \%$ CETS was added in the gel with TEOS pre-hydrolysis for $20 \mathrm{~h}$. Nevertheless, as the CETS content was further increased, the pore size of the sample decreased gradually and down to $3.5 \mathrm{~nm}$ with $15 \mathrm{~mol} \%$ CETS. Similarly, the pore volumes of the materials decreased from $0.78 \mathrm{~cm}^{3} / \mathrm{g}$ to $0.39 \mathrm{~cm}^{3} / \mathrm{g}$ as the CETS content increase from $3 \mathrm{~mol} \%$ to $15 \mathrm{~mol} \%$.

The counterpart samples prepared without TEOS prehydrolysis have larger surface areas, but smaller pore sizes and pore volumes. Moreover, the $D_{\mathrm{p}}$ values of these 
Table 1

Physical and textural properties of amorphous silica and SBA-15 materials functionalized with CETS

\begin{tabular}{|c|c|c|c|c|c|c|}
\hline Sample & $D_{\mathrm{p}}{ }^{\mathrm{a}}(\mathrm{nm})$ & $D_{\mathrm{a}}^{\mathrm{b}}(\mathrm{nm})$ & $\operatorname{PSD}^{\mathrm{c}}(\mathrm{nm})$ & $S_{\mathrm{BET}}\left(\mathrm{m}^{2} / \mathrm{g}\right)$ & Micropore S.A. ${ }^{\mathrm{d}}\left(\mathrm{m}^{2} / \mathrm{g}\right)$ & Pore volume $\left(\mathrm{cm}^{3} / \mathrm{g}\right)$ \\
\hline $\mathrm{SiO}_{2}$ gel & 3.6 & 3.3 & 0.3 & 754 & 1 & 0.62 \\
\hline $\mathrm{SiO}_{2}-\mathrm{phSO}_{3} \mathrm{H}-3-\mathrm{P}$ & 5.0 & 5.1 & 1.0 & 616 & 0 & 0.78 \\
\hline $\mathrm{SiO}_{2}-\mathrm{phSO}_{3} \mathrm{H}-7-\mathrm{P}$ & 4.3 & 4.4 & 0.9 & 567 & 0 & 0.62 \\
\hline $\mathrm{SiO}_{2}-\mathrm{phSO}_{3} \mathrm{H}-10-\mathrm{P}$ & 3.8 & 4.0 & 0.8 & 490 & 0 & 0.49 \\
\hline $\mathrm{SiO}_{2}-\mathrm{phSO}_{3} \mathrm{H}-15-\mathrm{P}$ & 3.5 & 3.7 & 0.3 & 422 & 3 & 0.39 \\
\hline $\mathrm{SiO}_{2}-\mathrm{phSO}_{3} \mathrm{H}-7$ & 3.4 & 2.9 & 0.4 & 609 & 28 & 0.45 \\
\hline $\mathrm{SiO}_{2}-\mathrm{phSO}_{3} \mathrm{H}-10$ & 3.5 & 2.9 & 0.4 & 565 & 5 & 0.40 \\
\hline $\mathrm{SBA}-\mathrm{phSO}_{3} \mathrm{H}-5$ & 6.2 & 4.8 & 0.5 & 823 & 114 & 0.99 \\
\hline $\mathrm{SBA}-\mathrm{phSO}_{3} \mathrm{H}-10$ & 6.1 & 4.5 & 0.7 & 738 & 143 & 0.83 \\
\hline SBA-phSO ${ }_{3} \mathrm{H}-15$ & 5.4 & 3.8 & 1.2 & 563 & 188 & 0.53 \\
\hline SBA-PrSO ${ }_{3} \mathrm{H}-10$ & 6.2 & 5.3 & 0.7 & 837 & 25 & 1.14 \\
\hline
\end{tabular}

${ }^{\text {a }}$ The peak positions of the distribution curves by $\mathrm{BJH}$.

${ }^{b}$ Average pore diameter calculated from the distribution curves by BJH.

${ }^{c}$ The peak width at half maximum height of the BJH peak.

${ }^{\mathrm{d}}$ Calculated by $t$-plot curves.

samples are slightly greater than the $D_{\text {a }}$ ones, indicating that the pore diameters in these materials are not very uniform. Since the profiles of BJH pore size distribution show only relatively narrow peaks in the mesopore region (Fig. 2B), the discrepancies are probably due to the presence of some micropores in these materials. The micropore surface areas of the functionalized materials were determined by $t$-plot curves and the results are shown in Table 1. The amorphous materials synthesized with TEOS prehydrolysis have negligible micropore surface areas, while those prepared without TEOS pre-hydrolysis have small amount of micropore surface areas. On the contrary, the sulfonic acid-functionalized SBA-15 materials contain relatively high micropore surface areas, which were considered to be formed by the occlusion of poly(ethylene oxide) chains of the P123 template in the silica matrix [48].

Thermogravimetric analyses (TGA) were conducted to examine the amount and thermal stability of the organic functional groups incorporated in the materials. Fig. 3 shows the weight loss and the derivative (DTG) profiles of the as-made functionalized silica materials containing $10 \mathrm{~mol} \%$ CETS in the synthesis mixtures with and without TEOS pre-hydrolysis. The weight losses at temperatures lower than $120^{\circ} \mathrm{C}$ are attributed to the losses of adsorbed water. The amount of adsorbed water in $\mathrm{SiO}_{2}-\mathrm{phSO}_{3} \mathrm{H}-10-$ $\mathrm{P}$ is less than that in $\mathrm{SiO}_{2}-\mathrm{phSO}_{3} \mathrm{H}-10$ (11 wt \% vs. $\left.15 \mathrm{wt} \%\right)$, indicating that the former has lower surface hydrophilicity. This may be because the material prepared without TEOS pre-hydrolysis has higher surface area and more micropores which are accessible by water molecules. A small weight loss (ca. $1 \%$ ) was observed on $\mathrm{SiO}_{2}-\mathrm{phSO}_{3} \mathrm{H}-10-\mathrm{P}$ around $260^{\circ} \mathrm{C}$, and that was attributed to the methoxy groups in the incompletely hydrolyzed CETS. On the contrary, no weight loss was observed on the counterpart $\mathrm{SiO}_{2}-\mathrm{phSO}_{3} \mathrm{H}-10$ in this temperature region, indicating that both TEOS and CETS were hydrolyzed completely when they were mixed simultaneously into the acid. The weight losses of ca. $20 \%$ at $400-600{ }^{\circ} \mathrm{C}$ are due to the decomposition of the phenylsulfonic acid groups incorpo-
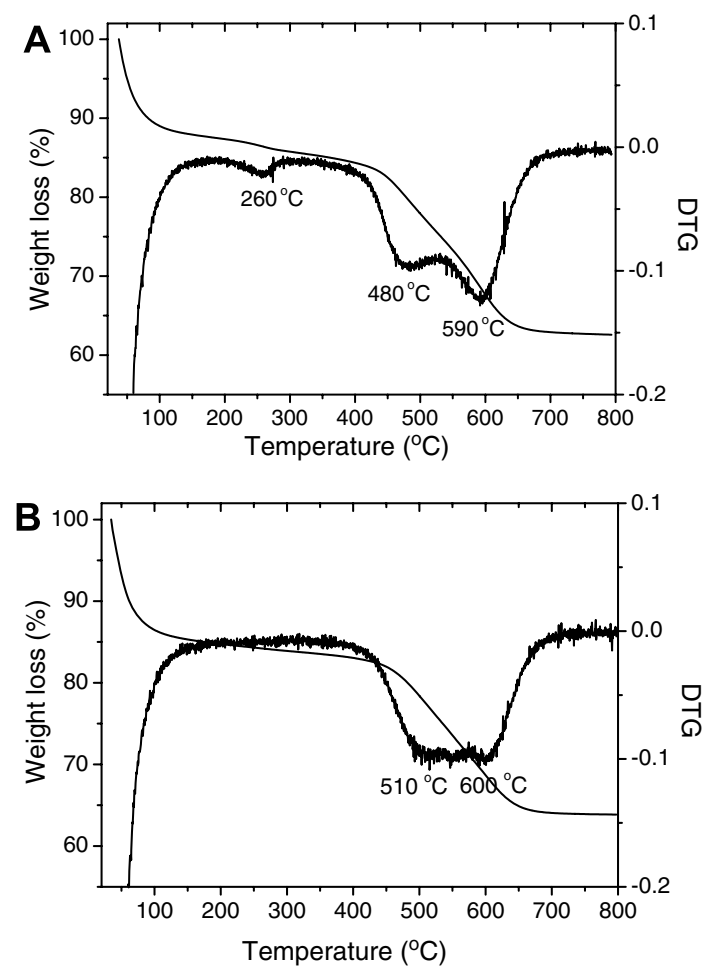

Fig. 3. TGA and DTG profiles of (A) $\mathrm{SiO}_{2}-\mathrm{phSO}_{3} \mathrm{H}-10-\mathrm{P}$ and (B) $\mathrm{SiO}_{2}-$ $\mathrm{phSO}_{3} \mathrm{H}-10$.

rated in the materials. The DTG profiles show two peaks in this temperature region, demonstrating that the phenylsulfonic acid groups were decomposed stepwise upon heating in air. It is also noticed that the organic moieties in $\mathrm{SiO}_{2}-\mathrm{phSO}_{3} \mathrm{H}-10-\mathrm{P}$ decomposed at slightly lower temperature than that in $\mathrm{SiO}_{2}-\mathrm{phSO}_{3} \mathrm{H}-10$. That might be due to that the sample synthesized with TEOS pre-hydrolysis contained larger pore size than its counterpart.

Qualitative identification of the organic functional groups in the materials was performed by FTIR spectroscopy. Fig. 4 illustrates the FTIR spectra of the functionalized amorphous materials with $10 \mathrm{~mol} \%$ CETS in 


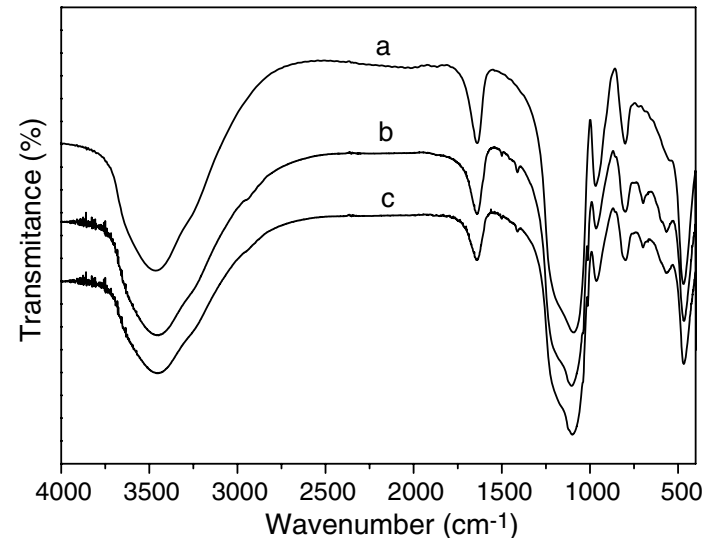

Fig. 4. FTIR spectra of (a) pure $\mathrm{SiO}_{2}$ reference, (b) $\mathrm{SiO}_{2}-\mathrm{phSO}_{3} \mathrm{H}-10-\mathrm{P}$, and (c) $\mathrm{SiO}_{2}-\mathrm{phSO}_{3} \mathrm{H}-10$.

comparison to that of pure silica gel prepared by TEOS hydrolysis under the same condition. Common to all samples are the bands around 1220, 1070, 794, and $471 \mathrm{~cm}^{-1}$ assigned to the typical $\mathrm{Si}-\mathrm{O}-\mathrm{Si}$ stretching and bending vibrations of condensed silica network and the peaks around $960 \mathrm{~cm}^{-1}$ corresponding to non-condensed $\mathrm{Si}-\mathrm{OH}$ groups $[49,50]$. The broad band around $3400 \mathrm{~cm}^{-1}$ and the strong peak around $1630 \mathrm{~cm}^{-1}$ are due to the stretching and bending vibrations of adsorbed $\mathrm{H}_{2} \mathrm{O}$. In comparison to the spectrum of the reference silica, the sulfonic acid functionalized materials have additional peaks at 566 and $698 \mathrm{~cm}^{-1}$ with medium intensity and two weak peaks at 1420 and $1500 \mathrm{~cm}^{-1}$. The low wavenumber peaks are assigned to the out-of-plane bending of the para di-substituted aromatic ring as well as the bending vibration of the sulfonic acid group, and the two weak peaks are bending vibrations of $\mathrm{C}-\mathrm{H}$ in aromatic rings [49]. These results confirm the incorporation of phenylsulfonic acid groups into the silica materials. The peaks corresponding to the $\mathrm{S}=\mathrm{O}$ stretching vibrations are normally observed in the range of $1000-1400 \mathrm{~cm}^{-1}$. However, these peaks cannot be resolved due to their overlap with the absorbance of $\mathrm{Si}-\mathrm{O}-\mathrm{Si}$ stretch in $1000-1130 \mathrm{~cm}^{-1}$ range and that of $\mathrm{Si}-$ $\mathrm{CH}_{2}-\mathrm{R}$ stretch in $1200-1250 \mathrm{~cm}^{-1}$ range. On the other hand, a broad absorbance in the range $2850-3000 \mathrm{~cm}^{-1}$ and a weak peak around $1450-1470 \mathrm{~cm}^{-1}$ are attributed to the stretching and bending vibration of methylene groups in the precursor, further confirming the incorporation of organic groups.

Solid state ${ }^{13} \mathrm{C}$ and ${ }^{29} \mathrm{Si} \mathrm{NMR} \mathrm{spectroscopy} \mathrm{was} \mathrm{proved}$ to be the most useful for providing chemical information regarding the condensation of organosiloxane and siloxane. Fig. 5A shows the ${ }^{29} \mathrm{Si}$ MAS NMR spectrum of the amorphous silica functionalized with $10 \mathrm{~mol} \%$ CETS prepared through TEOS pre-hydrolysis. Three distinct resonances for siloxane $\left[\mathrm{Q}^{n}=\mathrm{Si}(\mathrm{OSi})_{n}(\mathrm{OH})_{4-n}, n=2-4\right.$; $\mathrm{Q}^{2}$ at $-92 \mathrm{ppm}, \mathrm{Q}^{3}$ at $-103 \mathrm{ppm}$, and $\mathrm{Q}^{4}$ at $\left.-111 \mathrm{ppm}\right]$ and two weaker resonances for organosiloxane $\left[\mathrm{T}^{m}=\mathrm{RSi}\right.$ $(\mathrm{OSi})_{m}(\mathrm{OH})_{3-m}, \quad m=1-3 ; \mathrm{T}^{2}$ at $-56 \mathrm{ppm}$, and $\mathrm{T}^{3}$ at $-68 \mathrm{ppm}$ ] were clearly observed. The appearance of $\mathrm{T}^{m}$
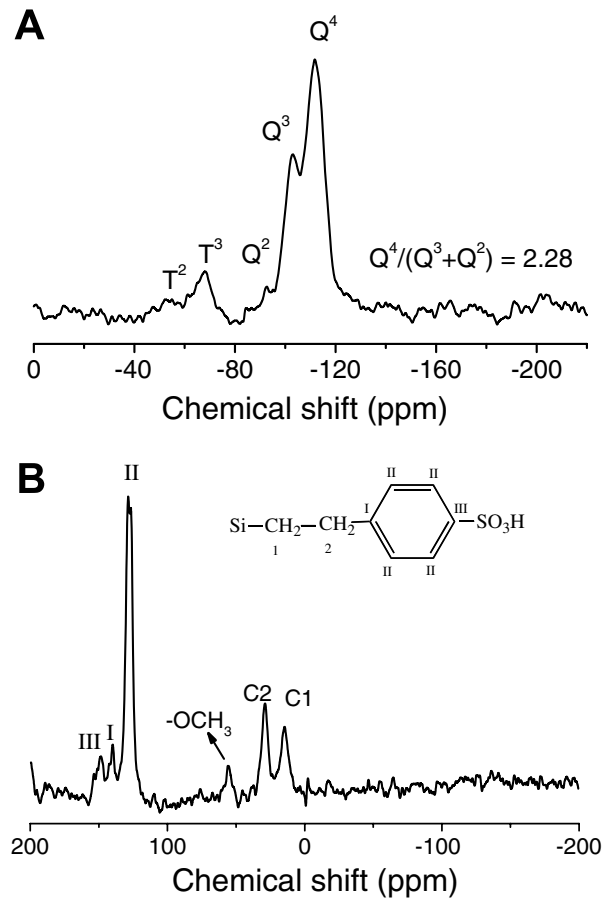

Fig. 5. (A) ${ }^{29} \mathrm{Si}$ MAS and (B) ${ }^{13} \mathrm{C}$ CP-MAS solid state NMR spectra of $\mathrm{SiO}_{2}-\mathrm{phSO}_{3} \mathrm{H}-10-\mathrm{P}$.

peaks with $\mathrm{T}^{3}$ predominant over $\mathrm{T}^{2}$ implies that the organosiloxane precursors are effectively condensed as a part of the silica framework [31]. The analysis of the integrated intensities of the $\mathrm{T}^{m}$ and $\mathrm{Q}^{n}$ signals gave the $\mathrm{T}^{m} /\left(\mathrm{T}^{m}+\mathrm{Q}^{n}\right)$ ratio of 0.11 , which is in good agreement with the theoretical value based on the CETS content in the synthesis mixture. On the other hand, the relative area ratio of $\mathrm{Q}^{4}$ / $\left(\mathrm{Q}^{3}+\mathrm{Q}^{2}\right)$ of 2.28 indicates that very high condensation extent of TEOS under the synthesis condition.

The ${ }^{13} \mathrm{C}$ CP-MAS NMR spectrum of $\mathrm{SiO}_{2}-\mathrm{phSO}_{3} \mathrm{H}-10$ $\mathrm{P}$ is illustrated in Fig. 5B. The peaks at 12.9 and $27.6 \mathrm{ppm}$ are attributed to the methylene $\mathrm{C}^{1}$ (adjacent to $\mathrm{Si}$ atom) and $\mathrm{C}^{2}$ (adjacent to phenyl ring) carbon atoms, respectively. Three peaks in down field region are assigned to carbons on the aromatic ring, and the peaks at 140.5, 127.4 and $147.9 \mathrm{ppm}$ correspond to $\mathrm{C}^{\mathrm{I}}, \mathrm{C}^{\mathrm{II}}$ and $\mathrm{C}^{\mathrm{III}}$ carbon atoms, respectively. These results further confirm that CETS precursors were co-condensed into the silica material and the organic moieties were not decomposed during the preparation procedure. The presence of a weak peak at $54.6 \mathrm{ppm}$, which is assigned to the carbon atom of methoxy groups $\left(\mathrm{Si}-\mathrm{OCH}_{3}\right)$, implies that small amount of the CETS precursors was not completely hydrolyzed [51,52]. That is in consistence with the observation in FTIR spectra. On the other hand, the hydrolysis of TEOS is considered relatively complete since no resonance NMR signals appeared around $60 \mathrm{ppm}$ which is assigned to the carbon (adjacent to $\mathrm{O}$ atom) of ethoxy groups $\left(\mathrm{Si}-\mathrm{OCH}_{2} \mathrm{CH}_{3}\right)[52,53]$.

The contents of phenylsulfonic acid groups in the functionalized materials were determined by $\mathrm{S}$ elemental analysis and the results are given in Table 2. It can be seen that CETS in the initial mixture has almost incorporated into 
Table 2

Sulfur contents and acid capacities of amorphous silica and SBA-15 materials functionalized with CETS

\begin{tabular}{|c|c|c|c|c|c|}
\hline \multirow[t]{2}{*}{ Sample } & \multicolumn{2}{|c|}{$\begin{array}{l}\text { S content } \\
(\mathrm{mmol} / \mathrm{g})\end{array}$} & \multicolumn{3}{|c|}{$\begin{array}{l}\text { Acid capacity } \\
(\mathrm{mmol} / \mathrm{g})\end{array}$} \\
\hline & EA & Theor. & $\mathrm{NaCl}$ & TMAC & TBAC \\
\hline $\mathrm{SiO}_{2}-\mathrm{phSO}_{3} \mathrm{H}-3-\mathrm{P}$ & 0.51 & 0.46 & 0.53 & 0.48 & 0.53 \\
\hline $\mathrm{SiO}_{2}-\mathrm{phSO}_{3} \mathrm{H}-7-\mathrm{P}$ & 1.02 & 0.73 & 1.14 & 1.04 & 0.99 \\
\hline $\mathrm{SiO}_{2}-\mathrm{phSO}_{3} \mathrm{H}-10-\mathrm{P}$ & 1.43 & 1.29 & 1.49 & 1.35 & 1.21 \\
\hline $\mathrm{SiO}_{2}-\mathrm{phSO}_{3} \mathrm{H}-15-\mathrm{P}$ & 1.78 & 1.73 & 1.72 & 1.50 & 1.35 \\
\hline $\mathrm{SiO}_{2}-\mathrm{phSO}_{3} \mathrm{H}-7$ & 1.05 & 0.73 & 1.06 & 0.96 & 0.83 \\
\hline $\mathrm{SiO}_{2}-\mathrm{phSO}_{3} \mathrm{H}-10$ & 1.38 & 1.29 & 1.43 & 1.18 & 1.05 \\
\hline SBA-phSO ${ }_{3} \mathrm{H}-5$ & 0.60 & 0.73 & 0.62 & 0.58 & 0.63 \\
\hline SBA-phSO ${ }_{3} \mathrm{H}-10$ & 1.10 & 1.29 & 1.12 & 1.02 & 1.00 \\
\hline $\mathrm{SBA}-\mathrm{phSO}_{3} \mathrm{H}-15$ & 1.32 & 1.73 & 1.38 & 1.20 & 1.06 \\
\hline SBA- $-\mathrm{PrSO}_{3} \mathrm{H}-10$ & 1.05 & 1.40 & 1.04 & 0.96 & 0.83 \\
\hline
\end{tabular}

the resulting materials through template-free routes. On the contrary, only about $80 \mathrm{~mol} \%$ CETS was incorporated into the SBA-15 materials synthesized in the presence of P123 template.

The accessibility of sulfonic acid centers in the sulfonic acid-functionalized materials was determined by titrating the filtrates with $\mathrm{NaOH}$ after the materials were ionexchanged with cations of various sizes, and the results are shown in Table 2 . When sodium chloride was used as the ion-exchange agent, the acid capacities obtained were very close to the $\mathrm{S}$ contents determined by EA in the sulfonic acid-functionalized materials, confirming that the chlorosulfonyl moieties in CETS precursors was completely in situ hydrolyzed to sulfonic acid groups under the synthesis condition. When cations of larger sizes such as $\mathrm{TMA}^{+}$and $\mathrm{TBA}^{+}$were used as the ion-exchange agents, the acid capacities of the amorphous materials prepared with TEOS pre-hydrolysis were almost unchanged for the sample with lowest CETS content $(3 \mathrm{~mol} \%)$, suggesting that all the phenylsulfonic acid groups in this sample were located on the surfaces of porous walls and easily accessed by the cations. As for the samples with higher CETS contents (especially for $\mathrm{SiO}_{2}-\mathrm{phSO}_{3} \mathrm{H}-10-\mathrm{P}$ and $\mathrm{SiO}_{2}$ $\mathrm{phSO}_{3} \mathrm{H}-15-\mathrm{P}$ ), the acid capacities of the samples decreased significantly as the size of the cation increases, indicating that a portion of the phenylsulfonic acid groups in these samples was embedded in the silica networks. Table 2 also shows that the preparation method influences the accessibility of phenylsulfonic acid groups in the materials. The samples prepared without TEOS pre-hydrolysis have lower acid capacities toward cation-exchange with $\mathrm{TMA}^{+}$and $\mathrm{TBA}^{+}$than those prepared with TEOS pre-hydrolysis, even both have similar $\mathrm{S}$ contents. In other words, more phenylsulfonic acid groups were buried in the silica network for the materials prepared without TEOS pre-hydrolysis, although the latter samples have larger surface areas than the counterparts prepared with TEOS pre-hydrolysis. For phenylsulfonic acid-functionalized SBA-15 of ordered pore structure, the decrease in acid capacities with the increase in cation size was also seen for the materials with high CETS contents. Nevertheless, it is noticeable that the func- tionalized amorphous silica samples prepared with TEOS pre-hydrolysis have greater acid capacities than the functionalized SBA-15 or the counterparts prepared without TEOS pre-hydrolysis.

\subsection{Catalytic reactions}

The esterification of acetic acid with methanol and acetalization of chlorobenzaldehyde with methanol were used to test the catalytic activities of pheneylsulfonic acid-functionalized materials in liquid phase. In these two reactions, no by-products other than methyl acetate and 1-chloro-4dimethoxymethyl-benzene formed for esterification and for acetalization, respectively, were observed by GC-mass and GC spectrometry. The activities of the reactions were expressed by methanol conversion for esterification and by chlorobenzadehyde conversion for acetalization, respectively. Table 3 shows the initial rates of esterification and acetalization over different catalysts. It can be seen that the initial rates over catalysts prepared by different routes are all increase with the phenylsulfonic acid loadings and get to the maximum at $10 \mathrm{~mol} \%$ acid loading. These results indicate that the initial rates were not only affected by the numbers of the accessible acidic centers but also the porous structure and surface area. The phenylsulfonic acid functionalized amorphous silica could reach the same high initial rates as SBA-15 materials when they were prepared with TEOS pre-hydrolysis. The formers are generally also catalytically more active than the counterparts prepared without TEOS pre-hydrolysis. The reaction results over the propylsulfonic acid-functionalized SBA-15 with $10 \mathrm{~mol} \%$ MPTS in the synthesis gel are also given in Table 3 for comparison. It gave the lowest initial rate in esterification reaction among the catalysts with similar $\mathrm{S}$ loadings, implying that phenylsulfonic acid-functionalized materials have higher initial rates in esterification due to the higher acid strength. As to the acetalization over catalysts of similar S loadings, the initial rate over propylsulfonic acid-functionalized SBA-15 was slightly lower than that of phenylsulfonic acid-functionalized SBA-15 (SBA-

Table 3

Initial rates for esterification of acetic acid with methanol and acetalization of chlorobenzaldehyde with methanol over sulfonic acid-functionalized silica materials

\begin{tabular}{|c|c|c|}
\hline Sample & Ester. $^{\mathrm{a}} \times 10^{4}(\mathrm{~mol} / \mathrm{g} \mathrm{s})$ & Acetal. $\times 10^{4}(\mathrm{~mol} / \mathrm{g} \mathrm{s})$ \\
\hline $\mathrm{SiO}_{2}$ gel & 0 & 0.3 \\
\hline $\mathrm{SiO}_{2}-\mathrm{phSO}_{3} \mathrm{H}-3-\mathrm{P}$ & 1.2 & 0.3 \\
\hline $\mathrm{SiO}_{2}-\mathrm{phSO}_{3} \mathrm{H}-7-\mathrm{P}$ & 1.9 & 2.1 \\
\hline $\mathrm{SiO}_{2}-\mathrm{phSO}_{3} \mathrm{H}-10-\mathrm{P}$ & 2.0 & 4.2 \\
\hline $\mathrm{SiO}_{2}-\mathrm{phSO}_{3} \mathrm{H}-15-\mathrm{P}$ & 2.0 & 3.9 \\
\hline $\mathrm{SiO}_{2}-\mathrm{phSO}_{3} \mathrm{H}-7$ & 1.6 & 2.3 \\
\hline $\mathrm{SiO}_{2}-\mathrm{phSO}_{3} \mathrm{H}-10$ & 1.7 & 3.5 \\
\hline $\mathrm{SBA}-\mathrm{phSO}_{3} \mathrm{H}-5$ & 1.5 & 0.4 \\
\hline SBA-phSO ${ }_{3} \mathrm{H}-10$ & 2.0 & 4.2 \\
\hline SBA-phSO 3 H-15 & 2.0 & 4.1 \\
\hline SBA-PrSO 3 H-10 & 1.4 & 3.5 \\
\hline
\end{tabular}

${ }^{\text {a }}$ The value subtracted by initial rate in homogeneous reaction value. 

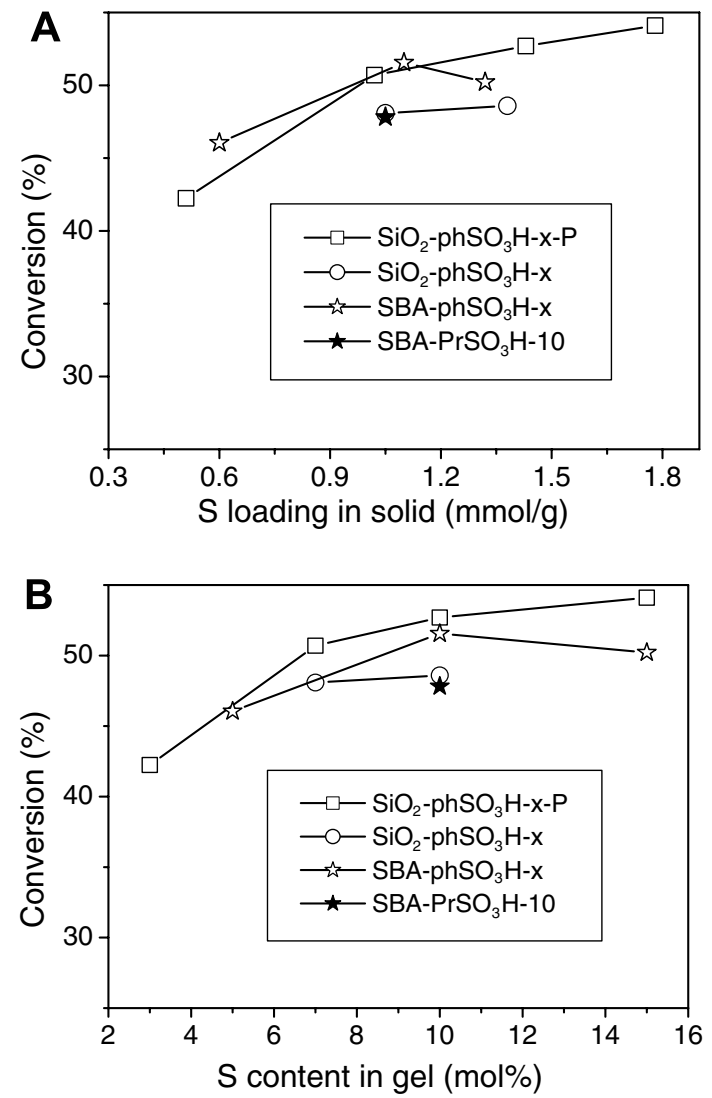

Fig. 6. Catalytic activities of sulfonic acid-functionalized silica materials in esterification of acetic acid with methanol at $50{ }^{\circ} \mathrm{C}$ for $4 \mathrm{~h}$, as a function of (A) S loading in the solid and (B) CETS content in the gel.

$\mathrm{phSO}_{3} \mathrm{H}-10$ ), but much higher than those of amorphous silica $\left(\mathrm{SiO}_{2}-\mathrm{phSO}_{3} \mathrm{H}-7-\mathrm{P}\right.$ and $\left.\mathrm{SiO}_{2}-\mathrm{phSO}_{3} \mathrm{H}-7\right)$. These results imply that the influence of acid strength on the initial rate of acetalization is not as significant as that of surface area and porous structure.

Fig. 6 displays the catalytic activities as a function of $\mathrm{S}$ loading in the catalysts for the esterification of acetic acid with methanol after $4 \mathrm{~h}$ of the reaction time at $50^{\circ} \mathrm{C}$. In general, the methanol conversion increases with the $\mathrm{S}$ loading in the catalysts. It can also be seen that the phenylsulfonic acid-functionalized amorphous catalysts prepared with TEOS pre-hydrolysis have similar conversions as the functionalized SBA-15, but higher conversions than the counterparts prepared without TEOS pre-hydrolysis or the propylsulfonic acid-functionalized SBA-15, based on similar S loading in the solids. However, between the two catalysts of higher activities, the amorphous materials could incorporate higher $\mathrm{S}$ contents in the solids than SBA-15 when the same amount of CTES was introduced in the synthesis gels. As a result, the amorphous catalysts could achieve the maximal conversions among the four kinds of materials in esterification of acetic acid with methanol.

Fig. 7 shows the catalytic activities as a function of $\mathrm{S}$ loading in the catalysts for the acetalization of chlorobenzaldehyde with methanol after $1 \mathrm{~h}$ at $30^{\circ} \mathrm{C}$. The conversion
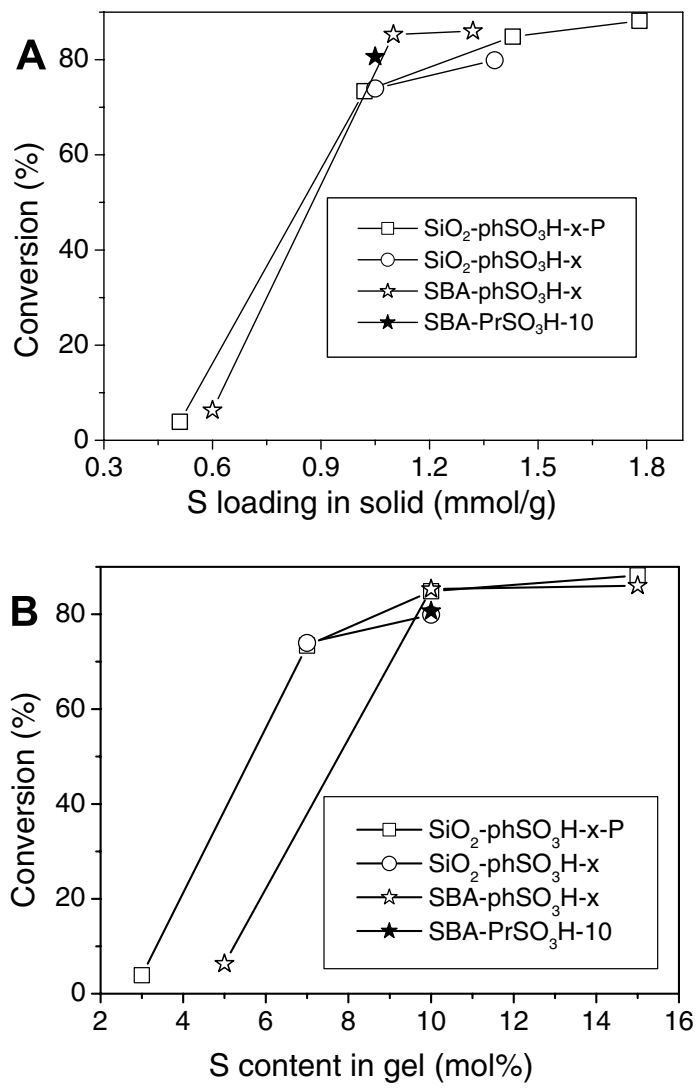

Fig. 7. Catalytic activities of sulfonic acid-functionalized silica materials in acetalization of chlorobenzaldehyde with methanol at $30^{\circ} \mathrm{C}$ for $1 \mathrm{~h}$, as a function of (A) S loading in the solid and (B) CETS content in the gel.

was found rather low over the catalysts with low $\mathrm{S}$ loadings. As the $\mathrm{S}$ loading was raised from ca. $0.6 \mathrm{mmol} / \mathrm{g}$ to $1.0 \mathrm{mmol} / \mathrm{g}$, the conversion increased markedly. That implies that the acid sites have cooperative effect on acetalization reaction. Moreover, the SBA-15 catalysts with ordered porous structures gave slightly higher conversion than the amorphous catalysts, based on similar S loadings. These results imply that large pore diameters of SBA-15 materials probably facilitate the diffusion of the relatively large reactant and product molecules encountered in this reaction. Nevertheless, the amorphous catalysts could still reach the maximal conversions as the $\mathrm{S}$ loading was further increased.

In order to examine the stability of the catalysts in the liquid phase, the $\mathrm{SiO}_{2}-\mathrm{phSO}_{3} \mathrm{H}-10-\mathrm{P}$ catalyst used in the esterification and the acetalization reactions was recycled four times after simple washing with methanol and drying at $200{ }^{\circ} \mathrm{C}$. The results were shown in Fig. 8. For the esterification, the catalytic activities only slightly decrease, demonstrating that most of the acid sites on the catalyst can be regenerate by simple washing and the catalyst can be used repeatedly under the present conditions. As for the acetalization, the catalytic activities gradually decrease from $85 \%$ to $25 \%$ with the recycling number. The decrease in conversion was proposed due to the reversible hydrolysis of acetal in the presence of water. These results were explained by 


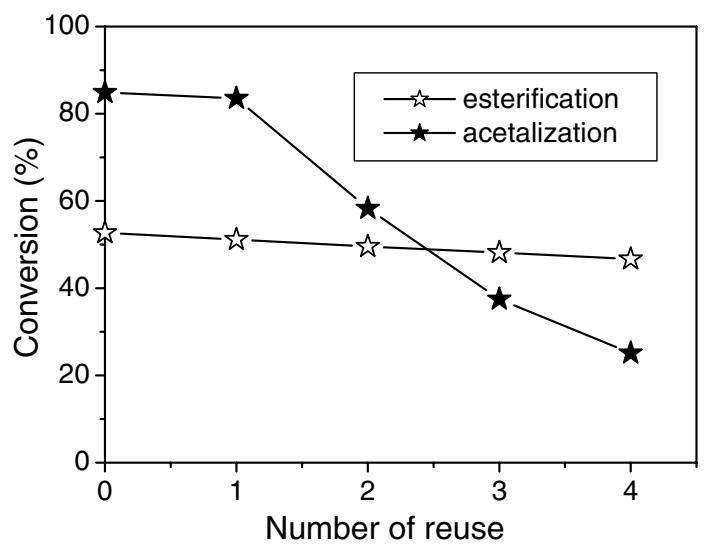

Fig. 8. Dependency of catalytic activity on reuse number over $\mathrm{SiO}_{2}$ $\mathrm{PrSO}_{3} \mathrm{H}-10-\mathrm{P}$ for esterification of acetic acid with methanol at $50{ }^{\circ} \mathrm{C}$ for $4 \mathrm{~h}$ and for acetalization of chlorobenzaldehyde with methanol at $30^{\circ} \mathrm{C}$ for $1 \mathrm{~h}$.

that accumulated amount of water might be retained in the pores of the regenerated catalyst.

\section{Conclusions}

The functionalized silica materials with different loadings of phenylsulfonic acid groups were prepared by a sample co-condensation of TEOS and CETS under strong acid condition. The materials contained mesoporous structure with narrow pore-size distribution. The samples prepared with TEOS pre-hydrolysis showed larger pore sizes and pore volumes than the counterparts prepared without TEOS pre-hydrolysis. Phenylsulfonic acid centers in the former materials were more accessible by large reactive molecules compared with the latter. When used as acid catalysts in liquid phase reaction, the phenylsulfonic acidfunctionalized silica prepared with TEOS pre-hydrolysis have better catalytic activities than the counterparts in esterification of acetic acid with methanol and acetalization of chlorobenzaldehyde with methanol, but similar activities to sulfonic acid-functionalized SBA-15 of large pore size. This synthesis method opens up an economical and environmentally friendly route for preparing future hybrid organic-inorganic catalytic materials avoiding the use of expensive organic templates and large amount of organic solvents.

\section{Acknowledgements}

This project was supported by the National Science Council, Taiwan. Acknowledgments are also extended to Ms. C.-W. Lu and Mr. C.-S. Kao of Instrumentation Center of National Taiwan University for the assistance in elemental and thermal analyses.

\section{References}

[1] H. Yoshitake, T. Yokoi, T. Tatsumi, Chem. Mater. 15 (2003) 1713.
[2] S. Inagaki, S. Ogata, Y. Goto, Y. Fukushima, Stud. Surf. Sci. Catal. 4 (1998) 249.

[3] A.P. Wight, M.E. Davis, Chem. Rev. 102 (2002) 3589.

[4] A. Stein, Adv. Mater. (Weinheim. Ger.) 15 (2003) 763.

[5] X.G. Wang, K.S.K. Lin, J.C.C. Chan, S. Cheng, J. Phys. Chem. B 109 (2005) 1763.

[6] M.M. Collinson, Mikrochim. Acta 129 (1998) 149

[7] V.S.Y. Lin, C.Y. Lai, J. Huang, S.A. Song, S. Xu, J. Am. Chem. Soc. 123 (2001) 11510.

[8] Y.V. Subba Rao, D. De Vos, P.A. Jacobs, Angew. Chem., Int. Ed. Engl. 36 (1997) 2661.

[9] D. Brunel, F. Fajula, J.B. Nagy, B. Deroide, M.J. Verhoef, L. Veum, J.A. Peters, H. Van Bekkum, Appl. Catal. A: Gen. 213 (2001) 73.

[10] J.S. Beck, J.C. Vartuli, W.J. Roth, M.E. Leonowicz, C.T. Kresge, K.D. Schmitt, C.T.W. Chu, D.H. Olson, E.W. Sheppard, S.B. McCullen, J.B. Higgins, J.L. Schlenker, J. Am. Chem. Soc. 114 (1992) 10834.

[11] P. Mukherjee, S. Laha, D. Mandal, R. Kumar, Stud. Surf. Sci. Catal. 129 (2000) 283.

[12] D. Brunel, Micropor. Mesopor. Mater. 27 (1999) 329.

[13] R.J.P. Corriu, L. Datas, Y. Guari, A. Mehdi, C. Reyé, C. Thieuleux, Chem. Commun. (2001) 763.

[14] L. Beaudet, K.Z. Hossain, L. Mercier, Chem. Mater. 15 (2003) 327.

[15] T. Yokoi, H. Yoshitake, T. Tatsumi, J. Mater. Chem. 14 (2004) 951.

[16] A. Walcarius, C. Delacote, Chem. Mater. 15 (2003) 4181.

[17] D.J. Macquarrie, D.B. Jackson, Chem. Commun. (1997) 1781.

[18] K. Shimizu, E. Hayashi, T. Hatamachi, T. Kodama, Y. Kitayama, Tetrahedron Lett. 45 (2004) 5135.

[19] E. Cano-Serrano, J.M. Campos-Martin, J.L.G. Fierro, Chem. Commun. (2003) 246.

[20] R.D. Badley, W.T. Ford, J. Org. Chem. 54 (1989) 5437.

[21] E. Cano-Serrano, G. Blanco-Brieva, J.M. Campos-Martin, J.L.G. Fierro, Langmuir 19 (2003) 7621.

[22] J.E.G. Mdoe, J.H. Clark, D.J. Macquarrie, Synlett (1998) 625.

[23] L.F. Albright, Oil Gas J. (1990) 71.

[24] K. Wilson, J.H. Clark, Pure Appl. Chem. 72 (2000) 1313.

[25] H. Ichihashi, H. Sato, Appl. Catal. A 221 (2001) 359.

[26] A. Commarieu, W. Hoelderich, J.A. Laffitte, M.P. Dupont, J. Mol. Catal. A: Chem. 182 (2002) 137.

[27] G.A. Olah, S.I. Pradeep, G.K.S. Prakash, Synthesis (1986) 513.

[28] F.J. Waller, R.W. Van Scoyoc, Chemtech 17 (1987) 438.

[29] A. Chakrabarti, M.M. Sharma, React. Polym. 20 (1993) 1.

[30] D. Margolese, J.A. Melero, S.C. Christiansen, B.F. Chmelka, G.D. Stucky, Chem. Mater. 12 (2000) 2448.

[31] S. Sadasivan, D. Khushalani, S. Mann, J. Mater. Chem. 13 (2003) 1023.

[32] S. Hamoudi, S. Kaliaguine, Micropor. Mesopor. Mater. 59 (2003) 195.

[33] J.G.C. Shen, R.G. Herman, K. Klier, J. Phys. Chem. B 106 (2002) 9975.

[34] Q. Yang, M.P. Kapoor, S. Inagaki, J. Am. Chem. Soc. 124 (2002) 9694.

[35] K. Wilson, A.F. Lee, D.J. Macquarrie, J.H. Clark, Appl. Catal. A 228 (2002) 127.

[36] I.K. Mbaraka, D.R. Radu, V.S.Y. Lin, B.H. Shanks, J. Catal. 219 (2003) 329.

[37] V.M.V. Rhijn, D.E. De Vos, B.F. Sels, W.D. Bossaert, P.A. Jacobs, Chem. Commun. (1998) 317.

[38] I. Diaz, F. Mohino, J. Perez-Pariente, E. Sastre, Appl. Catal. A: Gen. 205 (2001) 19.

[39] D. Das, J.F. Lee, S.F. Cheng, Chem. Commun. (2001) 2178.

[40] J.A. Melero, G.D. Stucky, R. Van Grieken, G. Morales, J. Mater. Chem. 12 (2002) 1664.

[41] X.G. Wang, C.C. Chen, S.Y. Chen, Y. Mou, S. Cheng, Appl. Catal. A 281 (2005) 47.

[42] I.K. Mbaraka, B.H. Shanks, J. Catal. 229 (2005) 365.

[43] M.A. Harmer, W.E. Farneth, Q. Sun, J. Am. Chem. Soc. 118 (1996) 7708. 
[44] M.A. Harmer, Q. Sun, M.J. Mlchalczyk, Z. Yang, Chem. Commun. (1997) 1803.

[45] A. Heidekum, M.A. Harmer, W.F. Hoelderich, J. Catal. 188 (1999) 230.

[46] I.J. Kijs, H.L.F. Van Ochten, C.A. Van Walree, J.W. Geus, L.W. Jenneskens, J. Mol. Catal. A: Chem. 188 (2002) 209.

[47] D. Zhao, J. Feng, Q. Huo, N. Melosh, G.H. Frederichson, B.F. Chmelka, G.D. Stucky, Science 279 (1998) 548.

[48] C. Yang, B. Zibrowius, W. Schmidt, F. Schüth, Chem. Mater. 15 (2003) 3739.
[49] M. Llusar, G. Monros, C. Roux, J.L. Pozzo, C. Sanchez, J. Mater. Chem. 13 (2003) 2505.

[50] G. Sartori, F. Bigi, R. Maggi, R. Sartorio, D.J. Macquarrie, M. Lenarda, L. Storaro, S. Coluccia, G. Martra, J. Catal. 222 (2004) 410.

[51] G. Cerveau, R.J.P. Corriu, C. Lepeytre, P.H. Mutin, J. Mater. Chem. 8 (1998) 2707.

[52] I. Diaz, C. Marquez-Alvarez, F. Mohino, J. Perez-Pariente, E. Sastre, J. Catal. 193 (2000) 283.

[53] W. Guo, J.Y. Park, M.O. Oh, H.W. Jeong, W.J. Cho, I.K. Kim, C.S. Ha, Chem. Mater. 15 (2003) 2295. 